\title{
Engaging Purchase Decision of Customers in Marketplace Channel: A Study of Fashion Online Retail
}

Submitted Date :

21 Juli 2020

Accepted Date :

04 November 2020

\author{
Dewi Mustikasari Immanuel \\ Universitas Ciputra ${ }^{1}$ \\ dewi.immanuel@ciputra.ac.id \\ Martina Apriliyani Maharia \\ Universitas Ciputra \\ Imaharia6@gmail.com
}

\section{Suggested Citation:}

Prasad, S., Garg, A., \& Prasad, S. (2018). Purchase Decision of Generation Y in an Online Environment.Marketing Intelligence \& Planning, 37(4), 372-385, https://doi.org/10.1108/MIP-02-2018-0070

\section{Abstract:}

This study aims to know the impact of Price, Trust, E-WOM, and Social Factor towards Purchase Decisions of online fesyen products in the marketplace. And Multiple Linear Regression analysis of SPSS been used in this study the population in this study are people who have shopped in marketplaces such as tokopedia, shopee and Bukalapak and live in Surabaya. The sampling technique used was purposive sampling with 385 samples. Data collection in this study was carried out by distributing questionnaires to respondents. The results of this study indicate that the factors that have the greatest influence on purchasing decisions for fashion products in the marketplace are trust, then followed by ease of shopping (practicality), product design, personal factors, e-WOM, price and the last is social factors. The data analysis results that Price, Trust, and Social Factors had positive and significant impact towards Purchase Decision, meanwhile E-WOM had been rejected.

Keywords: E-WOM, Social Factors, Price, Trust, Purchase Decision

\section{Abstrak:}

Penelitian ini bertujuan untuk mengetahui pengaruh Harga, Kepercayaan, E-WOM, dan Faktor Sosial terhadap Keputusan Pembelian produk fesyen secara online di marketplace) dengan menggunakan analisis Regresi Linier Berganda SPSS. Populasi dalam penelitian ini adalah masyarakat yang pernah berbelanja di marketplace seperti tokopedia, shopee dan bukalapak yang berdomisili di Surabaya. Teknik sampling yang digunakan adalah purposive sampling dengan 385 sampel. Pengumpulan data dalam penelitian ini dilakukan dengan menyebarkan kuesioner pada responden. Hasil penelitian ini menunjukkan bahwa Harga, Kepercayaan, dan Faktor Sosial berpengaruh signifikan dan positif terhadap Keputusan Pembelian produk fesyen secara online, namun tidak demikian dengan EWOM.

Kata Kunci: E-WOM, Faktor Sosial, Harga, Kepercayaan, Keputusan Pembelian

\section{JEL Classification: M31}




\section{Latar Belakang}

Perkembangan teknologi internet di Indonesia semakin pesat sehingga menyebabkan terjadinya perubahan dalam hal komunikasi dan informasi. Menurut Susenas (2018), 29,5\% masyarakat Indonesia memilih untuk mengakses media sosial ketika mendapatkan akses internet. Selain itu, masyarakat Indonesia juga melakukan berbagai kegiatan lain salah satunya membeli barang atau jasa. Pesatnya perkembangan internet membuat perilaku belanja masyarakat berubah yaitu dari offline menjadi online.

Belanja online adalah kegiatan jual beli yang berhubungan dengan media online (Astari \& Nugroho, 2017). Menurut We Are Social (2018), sepanjang tahun 2018 produk fesyen dan kecantikan menjadi produk yang paling diminati konsumen saat belanja online. Pertumbuhan penduduk yang terus meningkat dan tingginya minat konsumen terhadap fesyen membuka peluang bagi para pelaku bisnis untuk menjual berbagai macam produk fesyen. Berbagai promosi dilakukan baik secara online maupun offline namun hal itu belum cukup untuk mendorong keputusan pembelian konsumen.

Keputusan pembelian melibatkan beberapa pilihan konsumen sebelum melakukan pembelian (Hanaysha, 2018). Keputusan pembelian dipengaruhi oleh keunggulan produk, desain, promosi, media sosial, eWOM, kepercayaan, sikap merek, harga, kemudahan belanja, e-promosi, faktor pribadi, faktor sosial, pemasaran sosial media, emosional, kualitas, lingkungan, persepsi risiko dan keamanan (Prasad et al., 2018; Kudeshia \& Kumar, 2017; Istanti, 2017; Rehman et al., 2017; Bhaduri \& Stanforth, 2012; Nurwibowo \& Indriani, 2017; Adistya \& Idris, 2017; Hanaysha, 2018; Arda \& Andriany, 2019; Wahyuni \& Kurniawan, 2019). Dari sekian banyak faktor pendorong keputusan pembelian produk fesyen secara online, peneliti melakukan pra-survei terhadap 80 responden yaitu masyarakat yang pernah berbelanja produk fesyen melalui marketplace misalnya pada tokopedia, bukalapak dan shopee. Hasil pra-survei ditampilkan pada gambar berikut:

Gambar 1. Faktor Penyebab Pembelian Produk Fesyen Secara Online

MENGAPA MEMBELI PRODUK FESYEN SECARA ONLINE?

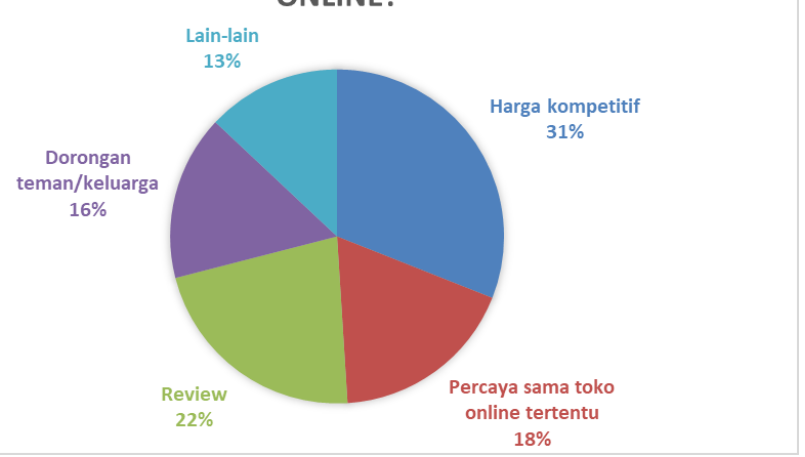

Sumber: Data diolah peneliti, 2020

Gambar 1 menunjukkan hasil pra-survei faktor pendorong keputusan pembelian produk fesyen secara online terhadap 80 responden. Faktor yang paling banyak dipilih adalah harga yang kompetitif (31\%), adanya review $(22 \%)$, karena percaya terhadap toko online tertentu $(18 \%)$, adanya dorongan teman dan atau keluarga $(16 \%)$, dan beragam jawaban lainnya (13\%) seperti kesulitan mencari produk secara offline dan produk hanya tersedia secara online, variasi produk, promosi (diskon dan promo), desain (model yang menarik), dan kualitas. Dapat dilihat dari hasil pra-survei bahwa promosi bukanlah faktor utama yang mendorong konsumen untuk melakukan pembelian, meskipun banyak marketplace yang telah melakukan promosi secara gencar. Sebaliknya, harga menjadi salah satu hal yang mayoritas diungkapkan responden dalam pra-survei. Sehingga, dalam penelitian ini mengambil faktor harga, kepercayaan, e-WOM, dan faktor sosial dengan tujuan untuk mengetahui lebih lanjut besar pengaruh dari tiap faktor tersebut dalam mendorong terjadinya keputusan pembelian fesyen secara online.

Penelitian ini menganalisis faktor pendorong keputusan pembelian produk fesyen dalam konteks marketplace. Marketplace adalah suatu website yang mempertemukan penjual dan pembeli untuk bertransaksi (Ardianti \& Widiartanto, 2019). Di marketplace, masyarakat bisa melakukan proses transaksi dengan pertukaran barang atau jasa untuk menghasilkan uang. Contoh marketplace adalah shopee, tokopedia dan bukalapak. Teori yang melandasi penelitian ini adalah consumer decision model yang dikenal dengan Engel-Blackwell-Miniard model. Consumer decision model memuat klasifikasi mengenai berbagai tahap pengambilan keputusan konsumen melalui pendekatan yang rasional sebagai panduan untuk menentukan pemikiran konsumen mengenai keputusan pembelian. Teori ini pertama kali dikembangkan pada tahun 1968 oleh Engel, Kollat dan 
Blackwell. Keterkaitan consumer decision model dengan penelitian yang dilakukan penulis adalah keinginan untuk mencari tahu secara detail faktor yang mendorong terjadinya keputusan pembelian. Model ini dibentuk dari enam poin proses pengambilan keputusan saat hendak melakukan pembelian yaitu munculnya kebutuhan, pencarian informasi, evaluasi alternatif, pembelian, konsumsi dan evaluasi pasca pembelian. Gambar 2.1 menunjukkan lima komponen dasar model ini yang terdiri dari stimulus, proses informasi, proses pengambilan keputusan, variabel proses pengambilan keputusan dan pengaruh lingkungan eksternal.

Gambar 2. Model Engel Kollat Blackwell

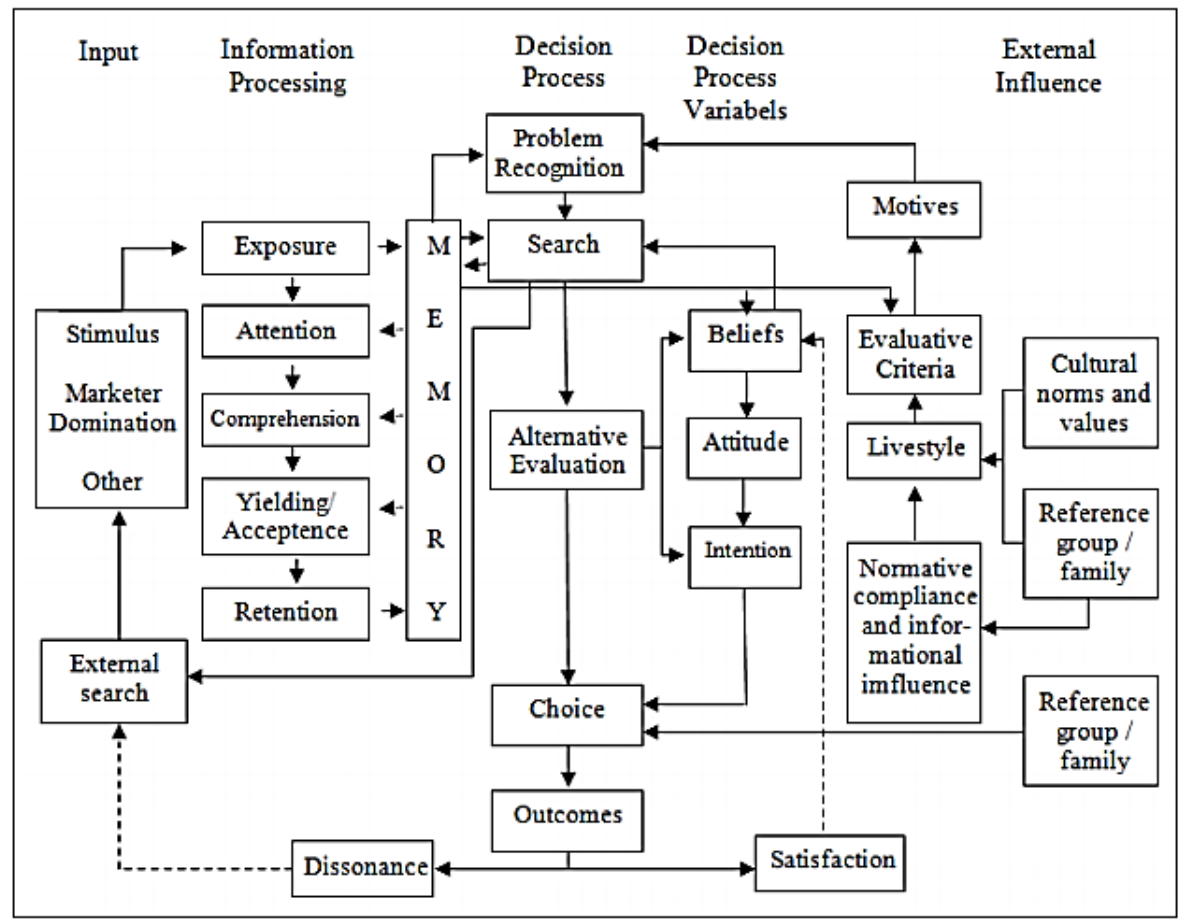

Sumber: Engel, Blackwell, Miniard, 1995

Gambar 2 menunjukkan bahwa terdapat tiga faktor eksternal yang dapat menentukan keputusan pembelian yaitu norma, nilai budaya dan kelompok referensi atau keluarga. Norma dan nilai budaya merupakan bagian dari gaya hidup konsumen, selain itu referensi kelompok atau keluarga mempengaruhi gaya hidup, kepatuhan normatif, pengaruh informasi dan pilihan konsumen. Norma, nilai budaya, kelompok referensi, keluarga, gaya hidup dan motivasi merupakan variabel yang dipertimbangkan dalam proses pengambilan keputusan pembelian (decision process).

\section{Keputusan Pembelian}

Keputusan pembelian adalah proses pemilihan dua atau lebih alternatif secara berurutan, dinamis dan fleksibel yang dibentuk oleh konsumen berupa berbagai aspek seperti budaya, pribadi, sosial dan psikologis yang saling berkaitan dan menunjukkan sejauh mana konsumen tertarik terhadap sebuah produk (Hall et al., 2017;Prasad et al., 2017;Widyastutir \& Said, 2017; Mukayati, 2019; Arda \& Andriany, 2019). Pembeli dapat melakukan banyak kegiatan sebelum mereka melakukan keputusan pembelian yang mencakup identifikasi masalah, pencarian informasi, pengembangan alternatif, pembelian dan evaluasi hasil pembelian secara keseluruhan (Chae \& Lee, 2013; Hall et al., 2017; Boardman \& McCormick, 2019).

\section{Harga}

Harga adalah sesuatu yang dibayarkan atas suatu barang atau jasa untuk mendapatkan manfaat dari barang atau jasa tersebut (Istanti, 2017; Bhaduri \& Stanforth, 2017). Harga dikenal sebagai elemen paling penting dalam pengambilan keputusan pembelian dan merupakan unsur dalam bauran pemasaran yang dapat mendatangkan keuntungan bagi para pelaku bisnis (Bolton \& Drew, 1991; Hall et al., 2017; Wahyuni \& Kurniawan, 2019; Rahman et al., 2020). Menurut Bhaduri \& Stanforth (2017), indikator-indikator harga yaitu: harga yang murah, kesesuaian harga dan kualitas produk, kesesuaian harga dengan kondisi produk, harga ekonomis. 
H1: Harga berpengaruh positif dan signifikan terhadap Keputusan Pembelian produk fesyen secara online di Marketplace.

\section{Kepercayaan (Trust)}

Kepercayaan adalah keadaan psikologis berupa niat dan harapan positif konsumen terhadap produk atau jasa tertentu (Rousseau et al., 1998; Harris \& Goode, 2004; Connolly \& Bannister, 2007; Gul, 2014; Prasad et al., 2017; Kamilullah et al., 2018; Punyatoya, 2019; Mukayati, 2019). Kepercayaan memiliki peran penting saat berbelanja online untuk mempengaruhi keputusan pembelian konsumen (Pan \& Chiou, 2011; Hall et al., 2017; Prasad et al., 2017). Kepercayaan juga dapat diartikan sebagai keyakinan konsumen terhadap karakteristik tertentu yang diwujudkan dengan perilaku baik (Coulter 2002; Kamilullah et al., 2018). Kepercayaan berevolusi dari pola pemikiran dan perasaan konsumen yang rasional (Lewis \& Weigert,1985; Punyatoya, 2019). Menurut Harris \& Goode, (2004); Connolly \& Bannister, (2007); Prasad et al., (2017), indikator-indikator kepercayaan adalah: memperoleh pengalaman yang baik, memperoleh informasi yang berguna, media sosial yang aman dan dapat diandalkan, mudah dipercaya, memperoleh kepuasan.

H2: Kepercayaan berpengaruh positif dan signifikan terhadap Keputusan Pembelian produk fesyen secara online di Marketplace.

\section{Electronic Word of Mouth (E-WOM)}

Electronic Word of Mouth (e-WOM) adalah pengembangan dari WOM berupa suatu pernyataan positif atau negatif secara online dari pelanggan atau mantan pelanggan yang mengarah terhadap ajakan kepada semua orang untuk menyukai bahkan menentang suatu produk atau perusahaan tertentu (Hennig-Thurau et al., 2004;Cheung \& Lee, 2008; Goyette et al., 2010; Bambauer-Sachse \& Mangold, 2011; Jeong \& Koo, 2015; Zhang et al., 2017; Kudeshia \& Kumar, 2017; Prasad et al., 2017; Rahman \& Mannan, 2018; Mukayati, 2019). Kehadiran e-WOM lebih kuat dari WOM karena menawarkan lebih banyak peluang bisnis dan jangkauan informasi yang lebih luas untuk konsumen (Jacobsen, 2018). E-WOM telah diterima oleh masyarakat luas mengingat bahwa banyak konsumen mempertimbangkan ulasan online sebelum membuat keputusan pembelian (Zhang et al., 2017). Menurut Goyette et al., (2010); Bambauer-Sachse \&Mangold, (2011); Prasad et al.,(2017), e-WOM terdiri dari empat indikator yaitu: membahas hal positif terkait produk atau merek tertentu, merekomendasikan produk atau merek tertentu, sering membaca ulasan online tentang kesan orang lain terhadap suatu produk, percaya diri dalam membeli produk ketika melihat ulasan online yang positif dari orang lain.

H3: E-WOM berpengaruh positif dan signifikan terhadap Keputusan Pembelian produk fesyen secara online di Marketplace.

\section{Faktor Sosial}

Faktor sosial merupakan segala interaksi sosial antara masyarakat baik secara langsung maupun tidak langsung (Bhaduri \& Stanforth, 2017; Gusrita \& Rahmidani, 2018). Lingkungan sosial dapat mempengaruhi konsumen saat hendak mengambil keputusan dalam melakukan pembelian karena terdapat hubungan saling ketergantungan dan interkoneksi antar individu. Konsumen lebih suka mencari persetujuan dari teman-teman dan lingkungan sekitar saat hendak melakukan pembelian untuk menambah kepercayaan diri (Bolton et al., 2013; Viswanathan \& Jain, 2013; Hyseni et al., 2015; Rehman et al., 2017; Zhang et al., 2017;Gusrita \& Rahmidani, 2018; Singh \& Srivastava, 2019). Nilai sosial berkaitan dengan apa yang orang lain katakan dan mencerminkan partisipasi masyarakat dan kelompok (Wiedmann et al., 2009; Loureiro et al., 2017; Prasad \& Garg, 2018). Menurut Bhaduri \& Stanforth (2017), indikator faktor sosial sebagai berikut: membuat konsumen merasa diterima orang sekitar, membuat konsumen untuk mendapat kesan yang baik dari lingkungan sekitarnya, keinginan konsumen untuk mendapat pengakuan dan persetujuan sosial.

H4: Faktor Sosial berpengaruh positif dan signifikan terhadap Keputusan Pembelian produk fesyen secara online di Marketplace.

Setelah melakukan analisa pada beberapa literatur dan mengacu pada berbagai sumber referensi penelitian terdahulu tersebut di atas, peneliti menemukan banyak ragam faktor yang dapat mendorong terjadinya keputusan pembelian, diantaranya adalah harga, kepercayaan, e-wom, faktor sosial, desain produk, kemudahan belanja, dan faktor pribadi. Tidak ada referensi yang dapat menyatakan secara tetap susunan faktor penyebab 
terjadinya keputusan pembelian. Dengan kata lain, setiap faktor disini memiliki kesamaan dasar konseptual atau seluruh faktor dapat mengindikasikan sebagai pendorong terjadinya hal yang sama yaitu keputusan pembelian. Oleh karena itu, studi ini ingin menganalisis lebih lanjut pengaruh harga, kepercayaan, E-WOM, dan faktor sosial terhadap terjadinya keputusan pembelian produk fesyen secara online pada jumlah responden yang lebih besar dari pra-survei yang telah dilakukan sebelumnya.

\section{Methodology}

Penelitian ini merupakan penelitian kuantitatif dengan mengukur dan menganalisis data yang dikumpulkan dan diolah menggunakan prosedur statistika (Abdillah \& Jogiyanto, 2015). Populasi dalam penelitian ini adalah masyarakat yang pernah berbelanja melalui marketplace seperti tokopedia, shopee, bukalapak dan lain-lain yang berdomisili di Surabaya. Sampel penelitian ini diambil dari populasi yang telah memenuhi kriteria dengan teknik purposive sampling, yaitu masyarakat yang berdomisli di Surabaya dan pernah berbelanja produk fesyen di marketplace seperti Tokopedia, Shopee dan Bukalapak. Oleh karena itu populasi dalam penelitian ini merupakan infinit population sehingga besaran sampel pada penelitian ini adalah 385 responden yang mengacu pada rumus Cosenza \& Davis (1993). Adapun model analisis dalam penelitian ini adalah sebagai berikut:

Gambar 3. Model Analisis Penelitian

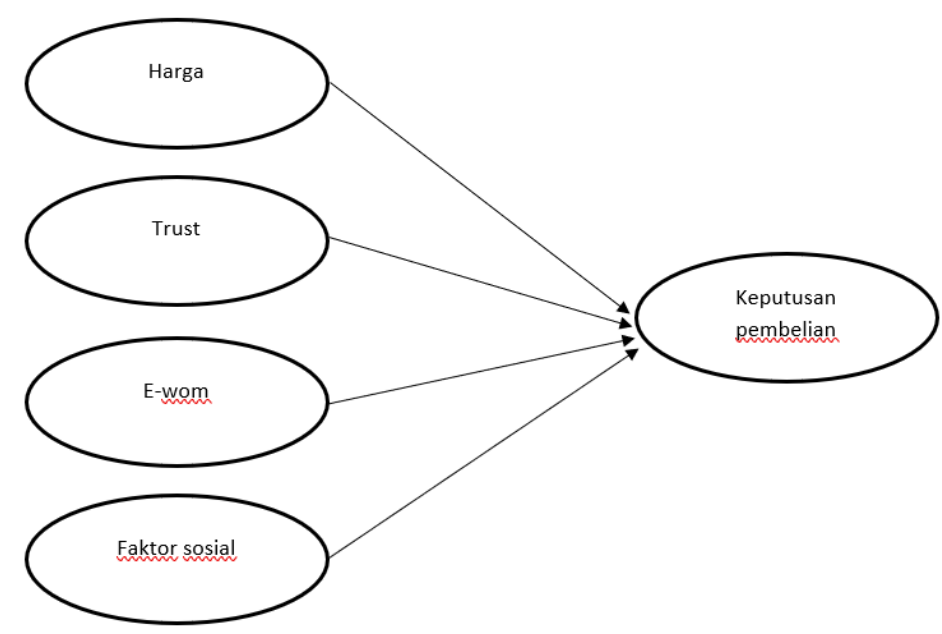

Sumber: Data diolah peneliti, 2020

Analisis data dalam penelitian ini menggunakan SPSS dengan tahapan pertama yaitu uji validitas untuk mengetahui kemampuan instrumen penelitian dalam mengukur apa yang seharusnya diukur, dan uji reliabilitas untuk dapat mengetahui tingkat konsistensi dan kestabilan alat ukur suatu konstruk (Abdillah \& Jogiyanto, 2015). Uji validitas dilakukan dengan korelasi bivariate mengacu pada nilai korelasi Pearson dimana nilai signifikansi adalah $<0.05$, dan uji reliabilitas mengacu pada nilai Cronbach's Alpha $>0.60$ (Sekaran, 1992). Tahapan kedua yaitu dengan melakukan uji asumsi klasik yang terdiri dari multikolinearitas dengan melihat nilai Tolerance $\geq$ 0,10 atau nilai VIF $\leq 10$, heterokedastisitas dengan uji koefisien korelasi Spearman's rho dimana jika korelasi antar variable independent dengan residual harus memiliki signifikansi $>0.05$, dan uji normalitas yang bertujuan untuk mengetahui variabel pengganggu atau residual memiliki distribusi normal atau tidak, ini dengan melihat pada signifikansi Kolmogorov-smirnov yang seharusnya > 0.05 (Ghozali, 2016). Tahapan ketiga adalah untuk menguji goodness of fit model penelitian melalui analisis regresi linier berganda yang terdiri dari koefisien determinasi, uji statistik $t$, dan uji statistik F.

\section{Hasil Penelitian}


Uji Validitas dengan menggunakan metode korelasi Pearson menunjukkan nilai signifikansi dari tiap item pada masing-masing variable Harga, Kepercayaan, E-WOM, dan Faktor Sosial adalah $0.000<0.05$, sehingga dapat dikatakan seluruh instrumen penelitian yang digunakan mampu menjadi pengukur tiap variabel tersebut. Selanjutnya untuk uji Reliabilitas menunjukkan hasil bahwa nilai Cronbach's Alpha dari setiap variabel adalah > 0.6, sehingga dapat dikatakan bahwa tiap instrumen penelitian memiliki konsistensi apabila pengukuran dilakukan pengulangan kembali.

Tabel 1. Cronbach's Alpha Values

\begin{tabular}{|c|c|c|}
\hline Variabel & Number of Items & $\begin{array}{c}\text { Cronbach's } \\
\text { Alpha }\end{array}$ \\
\hline Herga & 4 & 0.883 \\
\hline Kepercayaan & 5 & 0.823 \\
\hline E-wom & 4 & 0.817 \\
\hline Faktor sosial & 3 & 0.638 \\
\hline $\begin{array}{c}\text { Keputusan } \\
\text { pembelian }\end{array}$ & 3 & 0.797 \\
\hline
\end{tabular}

Sumber: Data diolah peneliti, 2020

Uji multikolinearitas menunjukkan hasil nilai Tolerance tiap variabel lebih dari 0.10 dan nilai VIF kurang dari 10 , sehingga dapat dikatakan bahwa antar variabel independen dalam model regresi pada penelitian ini tidak terjadi multikolinearitas.

Tabel 2. Collinearity Statistics Values

\begin{tabular}{|c|c|c|}
\hline \multirow{2}{*}{ Variabel } & \multicolumn{2}{|c|}{ Collinearity Statistics } \\
\cline { 2 - 3 } & Tolerance & VIF \\
\hline Harga & .577 & 1.734 \\
\hline Kepercayaan & .575 & 1.740 \\
\hline E-wom & .962 & 1.039 \\
\hline Faktor sosial & .936 & 1.069 \\
\hline
\end{tabular}

Sumber: Data diolah peneliti, 2020

Uji heterokedastisitas menunjukkan bahwa korelasi antara tiap variabel independent dengan Unstandardized Residual pada uji Spearman's rho memiliki nilai signifikansi (2-tailed) lebih dari 0.05, sehingga dapat disimpulkan tidak terjadi masalah heterokedastisitas.

Tabel 3. Spearman's rho Values

\begin{tabular}{|l|l|l|}
\hline $\begin{array}{l}\text { Spearman's rho } \\
\text { Sig. (2-tailed) }\end{array}$ & \multicolumn{1}{|c|}{ Variabel } & \multicolumn{1}{c|}{$\begin{array}{c}\text { Unstandardized } \\
\text { Residual }\end{array}$} \\
\cline { 2 - 3 } & Harga & .221 \\
\cline { 2 - 3 } & Kepercayaan & .356 \\
\cline { 2 - 3 } & E-wom & .809 \\
\cline { 2 - 3 } & Faktor sosial & .637 \\
\hline
\end{tabular}

Sumber: Data diolah peneliti, 2020

Uji normalitas yang dilakukan menunjukkan hasil besarnya nilai Kolmogorov-smirnov adalah 0.042 dan signifikan pada 0.092 yang lebih besar dari 0.05 , sehingga dapat dinyatakan bahwa data residual terdistribusi normal dan dapat dilanjutkan ke uji t dan uji F.

Tabel 4. Kolmogorov-smirnov Value

\begin{tabular}{|l|l|}
\hline & Unstandardized Residual \\
\hline Test statistic & .042 \\
\hline Asymp. Sig. (2-tailed) & .092 \\
\hline
\end{tabular}

Sumber: Data diolah peneliti, 2020

Selanjutnya, untuk menguji hipotesis penelitian maka dilakukan analisis regresi berganda untuk mengetahui pengaruh variabel independen Harga, Kepercayaan, E-WOM, dan Faktor Sosial terhadap variabel dependen Keputusan Pembelian.

Berikut ini adalah hasil dari analisis regresi berganda seperti tampak pada Tabel 5, Tabel 6, dan Tabel 7. 
Tabel 5. Koefisien Determinasi

\begin{tabular}{|c|c|c|c|c|}
\hline Model & $\mathbf{R}$ & $\begin{array}{c}\mathbf{R} \\
\text { Square }\end{array}$ & $\begin{array}{c}\text { Adjusted } \mathbf{R} \\
\text { Square }\end{array}$ & $\begin{array}{c}\text { Std. Error of the } \\
\text { Estimate }\end{array}$ \\
\hline 1 & .687 & .472 & .467 & .51886 \\
\hline
\end{tabular}

Sumber: Data diolah peneliti, 2020

Tabel 6. ANOVA

\begin{tabular}{|c|c|c|c|c|c|c|}
\hline Model & & $\begin{array}{c}\text { Sum of } \\
\text { quares }\end{array}$ & $\mathrm{df}$ & $\begin{array}{c}\text { Mean } \\
\text { Square }\end{array}$ & $\mathrm{F}$ & Sig. \\
\hline \multirow{2}{*}{1} & Regression & 91,594 & 4 & 22,898 & 85,057 & $\begin{array}{c}.000 \\
\mathrm{~b}\end{array}$ \\
\cline { 2 - 7 } & Residual & 102,301 & 380 & .269 & & \\
\cline { 2 - 7 } & Total & 193,895 & 384 & & & \\
\hline
\end{tabular}

Sumber: Data diolah peneliti, 2020

Tabel 7. Coefficients

\begin{tabular}{|c|c|c|c|c|c|c|}
\hline & & \multicolumn{2}{|c|}{ Unstandardized Coefficients } & \multirow{2}{*}{$\begin{array}{c}\text { Standardized } \\
\text { Coefficients } \\
\text { Beta } \\
\end{array}$} & \multirow[t]{2}{*}{$t$} & \multirow[t]{2}{*}{ Sig. } \\
\hline \multicolumn{2}{|c|}{ Model } & B & Std. Error & & & \\
\hline \multirow[t]{5}{*}{1} & (Constant) & 234 & 227 & & 1.034 &, 302 \\
\hline & AVX1 & 218 & 052 & 204 & 4,156 & 000 \\
\hline & AVX2 & 557 & 057 & 479 & 9,752 & 000 \\
\hline & AVX3 & 057 & 041 & 053 & 1,396 & ,164 \\
\hline & AVX4 & 129 & 037 & 0132 & 3,430 & 001 \\
\hline
\end{tabular}

Sumber: Data diolah peneliti, 2020

Hasil uji hipotesis pada Tabel 7 menunjukkan terdapat pengaruh signifikan dari Harga, Kepercayaan, dan Faktor Sosial terhadap Keputusan Pembelian dengan nilai Adjusted $R$ Square pada Tabel 5 sebesar 0.467 , yang artinya $46.7 \%$ Keputusan Pembelian produk fesyen secara online dapat dijelaskan oleh variabel Harga, Kepercayaan, dan Faktor Sosial, sedangkan sisanya sebesar $53.3 \%$ disebabkan oleh faktor lainnya diluar penelitian ini. Dan pada Tabel 6 menunjukkan nilai $\mathrm{F}$ hitung sebesar 85,057 dengan probabilitas signifikansi .000 yang lebih kecil dari 0.05 , sehingga dapat dikatakan model regresi dapat digunakan untuk memprediksi Keputusan Pembelian atau dengan kata lain variabel Harga, Kepercayaan, dan Faktor Sosial secara serentak dan signifikan mempengaruhi Keputusan Pembelian produk fesyen secara online. Pada Tabel 7, dari keempat variabel yang dimasukkan dalam model regresi, variabel E-WOM tidak memiliki pengaruh terhadap Keputusan Pembelian, hal ini dapat dilihat dari probabilitas signifikansi E-WOM yang sebesar 0.164 lebih besar dari 0.05 . Selain itu, variabel lainnya yaitu Harga (Sig 0.000), Kepercayaan (Sig 0.000), dan Faktor Sosial (0.001) ditemukan berpengaruh positif dan signifikan terhadap Keputusan Pembelian produk fesyen secara online.

\section{Pembahasan}

\section{Harga dan Keputusan Pembelian}

Dari hasil uji t menunjukkan bahwa Harga memiliki pengaruh yang signifikan dan positif terhadap keputusan pembelian produk fesyen secara online. Hal ini selaras dengan pernyataan Arda \& Andriany (2019) yang menyatakan bahwa harga adalah pendorong keputusan pembelian secara online dimana menurut Bhaduri \& Stanforth (2017) sebaiknya harga yang ditawarkan dari suatu produk atau jasa dapat dijangkau oleh berbagai kalangan yang artinya harga yang murah dan atau kompetitif lebih dapat menarik konsumen untuk melakukan pembelian, dan harga haruslah sesuai dengan kualitas dan kondisi produk yang ditawarkan konsumen saat ini juga menyesuaikan budget yang dimiliki dengan harga suatu produk.

\section{Kepercayaan dan Keputusan Pembelian}


Dari hasil uji t menunjukkan bahwa kepercayaan memiliki pengaruh yang signifikan dan positif terhadap keputusan pembelian produk fesyen secara online. Hal sejalan dengan Hall et al., (2017) dan Prasad et al., (2018) yang menyatakan bahwa kepercayaan memiliki peran penting saat belanja online untuk mempengaruhi keputusan pembelian. Kepercayaan dapat diartikan sebagai keyakinan konsumen terhadap karakteristik tertentu yang diwujudkan dengan perilaku baik (Kamilullah, et al., 2018), dimana keyakinan dapat diperoleh dari pengalaman positif sebelumnya, kepuasan saat berbelanja, kemudahan media online yang digunakan, dan kredibilitas toko (Harris \& Goode, (2004); Connolly \& Bannister, (2007); Prasad et al., (2017)). Hal ini sejalan dengan pendapat konsumen di lapangan yang menyatakan bahwa semakin terpercayanya suatu toko, semakin menarik konsumen untuk melakukan pembelian.

\section{E-WOM dan Keputusan Pembelian}

Dari hasil uji t ditemukan bahwa E-WOM tidaklah memiliki pengaruh terhadap Keputusan Pembelian produk fesyen secara online. Hal ini bertolak belakang dengan pernyataan Zhang et al., (2017) yang menyatakan bahwa konsumen sangat mempertimbangkan ulasan sebelum melakukan pembelian online, dimana kehadiran E-WOM lebih kuat dari WOM karena menawarkan lebih banyak peluang bisnis dan jangkauan informasi yang lebih luas untuk konsumen (Jacobsen, 2018). Mengingat di era perkembangan internet saat ini, E-WOM telah diterima oleh masyarakat luas mengingat bahwa banyak konsumen mempertimbangkan ulasan online sebelum membuat keputusan pembelian (Zhang et al., 2017), karena di dalam E-WOM seringkali ditemukan bahasan positif tentang suatu produk, sehingga ini menjadi suatu rekomendasi tersendiri bagi calon konsumen yang akan membeli produk tersebut (Goyette et al., (2010); Bambauer-Sachse \&Mangold, (2011); Prasad et al.,(2017)). Hal ini dapat dikarenakan dari banyak penelitian sebelumnya tersebut di atas tentang E-WOM cenderung membagi E-WOM menjadi variabel yang lebih spesifik lagi seperti E-WOM Credibility, E-WOM Quality, dan E-WOM Quantity sehingga dalam pengukurannya menggunakan instrumen penelitian yang lebih spesifik bila dibandingkan hanya sekedar mengukur E-WOM saja.

\section{Faktor Sosial dan Keputusan Pembelian}

Dari hasil uji t menunjukkan bahwa Faktor sosial memiliki pengaruh yang signifikan dan positif terhadap keputusan pembelian produk fesyen secara online. Hal ini sejalan dengan penelitian Hanaysha (2018), yang menyatakan bahwa faktor sosial memiliki pengaruh positif dan signifikan terhadap keputusan pembelian. Ini dikarenakan konsumen cenderung lebih suka mencari persetujuan dari teman-teman dan lingkungan sekitar saat hendak melakukan pembelian untuk menambah kepercayaan diri (Bolton et al., 2013; Viswanathan \& Jain, 2013; Hyseni et al., 2015; Rehman et al., 2017; Zhang et al., 2017;Gusrita \& Rahmidani, 2018; Singh \& Srivastava, 2019). Nilai sosial berkaitan dengan apa yang orang lain katakan dan mencerminkan partisipasi masyarakat dan kelompok (Wiedmann et al., 2009; Loureiro et al., 2017; Prasad \& Garg, 2018), dengan kata lain dapat diartikan bahwa penilaian orang lain terkait selera fesyen seseorang dapat mendorong terjadinya pembelian produk fesyen secara online.

\section{Kesimpulan}

Keputusan Pembelian dapat dipengaruhi oleh banyak hal yang menjadi pertimbangan konsumen untuk membeli, dan sampai saat ini tidak ada faktor tetap yang dapat dinyatakan sebagai penyebab pasti terjadinya keputusan pembelian. Dalam penelitian kali ini menghasilkan diterimanya hipotesis 1 yaitu Harga, hipotesis 2 yaitu Kepercayaan, dan hipotesis 4 yaitu Faktor Sosial berpengaruh positif dan signifikan terhadap Keputusan Pembelian, sedangkan untuk hipotesis 3 yaitu E-WOM ditolak karena tidak berpengaruh.

\section{Saran}

Disarankan bagi para penggerak bisnis fesyen pada jejaring online marketplace maupun pengembang marketplace itu sendiri agar lebih kreatif dalam menonjolkan sisi positif produk yang dijual serta didukung dengan ulasan riil konsumen berdasarkan pengalaman konsumen tentang produk tersebut guna meningkatkan rasa percaya konsumen atas produk yang dibelinya, juga toko dan marketplace yang dikunjunginya secara online. Sehingga dengan meningkatnya kepercayaaan konsumen maka kecenderungan konsumen untuk bisa merekomendasikan kepada orang lain akan lebih meningkat.

Perlu diketahui juga, bahwa konsumen sebelum membeli suatu produk, lebih suka mencari persetujuan dari teman-teman dan lingkungan sekitar terlebih dulu saat hendak melakukan pembelian agar lebih yakin dan percaya diri, ini menunjukkan lingkungan sosial sekitar konsumen pun memainkan peranan yang penting dalam proses keputusan pembelian konsumen, agar lingkungan sosial konsumen memberikan rekomendasi atau 
dorongan pengaruh yang positif, maka sebaiknya penggerak bisnis fesyen di jejaring marketplace memberikan layanan dan kualitas yang baik agar terbentuk memori pengalaman yang positif tentang suatu produk yang mengarah pada pengaruh sosial di lingkungan konsumen.

Dan bagi peneliti lainnya, dapat menjadikan variabel E-WOM dalam penelitian ini sebagai kesenjangan penelitian yang memungkinkan untuk diteliti kembali dengan lebih mendetilkan pada bagaian E-WOM Credibility, E-WOM Quality, dan E-WOM Quantity. 
Daftar Pustaka

Abdillah, Willy., \& Jogiyanto (2015). Partial Least Square (PLS) Alternatif Structural Equation Modeling (SEM) dalam Penelitian Bisnis. Andi

Adistya, C., \& Idris. (2017).Analisis Pengaruh Kualitas Online Word-of-Mouth dan Keamanan Terhadap Minat Beli Dengan Kepercayaan Sebagai Variabel Intervening pada Pembelian Produk Fashion di Situs Zalora Indonesia di Semarang.Diponegoro Journal of Management, 6(3), 1-11. http://ejournals1.undip.ac.id/index.php/dbr

Arda, M., \& Andriany, D. (2019). Analisis Faktor Stimuli Pemasaran dalam Keputusan Pembelian Online Produk Fashion Pada Generasi Z. Festival Riset IImiah Manajemen Dan Akuntansi, FEB Universitas Muhammadiyah Sumatera Utara, 2010(2), 433-439.

Ardianti, A. N., \& Widiartanto. (2019). Pengaruh Online Customer Review dan Online Customer Rating terhadap Keputusan Pembelian melalui Marketplace Shopee . Jurnal IImu Administrasi Bisnis, 1-11. http://teknonisme.com

Astari, D., \& Nugroho, C. (2017). Motivasi Pembelian Impulsif Online.Channel. 5(2), 33-46.

Bambauer-Sachse, S., \& Mangold, S. (2011). Brand Equity Dilution Through Negative Online Word-Of-Mouth Communication.Journal of Retailing and Consumer Services, 18(1), 38-45. https://doi.org/10.1016/j.jretconser.2010.09.003

Bhaduri, G., \& Stanforth, N. (2012). To ( Or Not To ) Label Products as Artisanal : Effect of Fashion Involvement On Customer Perceived Value. https://doi.org/10.1108/JPBM-04-2016-1153

Boardman, R., \& McCormick, H. (2019). The Impact of Product Presentation On Decision-Making and Purchasing.Qualitative Market Research, 22(3), 365-380. https://doi.org/10.1108/QMR-09-2017-0124

Bolton, R. N. (1991). A Longitudinal Analysis of the Impact of Service Changes on Customer Attitudes. Journal of Marketing. https://doi.org/10.2307/1252199

Bolton, R. N., Hoefnagels, A., Parasuraman, A. P., \& Migchels, N. (2013). Understanding Generation Y and Their Use of Social Media: A Review and Research Agenda. Journal of Service Management.https://doi.org/10.1108/09564231311326987

Chae, S. W., \& Lee, K. C. (2013). Exploring The Effect of The Human Brand On Consumers' Decision Quality in Online Shopping: An Eye-Tracking Approach. Online Information Review, 37(1), 83-100.

Chan, K. H. T., Cheung, M. K. C., \& Lee, W. Y. Zach. (2017). The State Of Online Impulse-Buying Research: A Literature Analysis. Information Management. 54(2), 204-217.

Cheung, C. M., \& Lee, M. K. O. (2008). The Impact of Electronic Word-of-Mouth The Adoption of Online Opinions in Online Customer Communities. Internet Research, 18(3), 229-247

Connolly, R., \& Bannister, F. (2007). Consumer Trust in Internet Shopping in Ireland: Towards The Development of A More Effective Trust Measurement Instrument.Journal of Information Technology, 22(2), 102-118. https://doi.org/10.1057/palgrave.jit.2000071

Coulter. (2002). Whatever Happened to Shared Decision-Making? 185-186

Davis, D., \& Cosenza, R. M. (1993). Business Research for Decision Making (3rded.). Belmont, CA.: Wadsworth Inc.

Engel, J. F., Blackwell, R. D., Miniard, P. W. (1995). Consumer Behavior. Dryden Press Ghozali, I. (2016). Aplikasi Analisis Multivariate (8th ed.). Badan Penerbit - Undip.

Goyette, I., Ricard, L., Bergeron, J.,\&Marticotte., F. (2010). E-WOM Scale: Word-Of-Mouth Measurement Scale for E-Services Context. Canadian Journal of Administrative Sciences/Revue Canadienne Des Sciences de l'Administration, 27(1), 5-23.

Gul, R. (2014). The Relationship Between Reputation, Customer Satisfaction, Trust and Loyalty. Journal of Public Administration and Governance, 4(3).

Gusrita, D., \& Rahmidani, R. (2018). Pengaruh Marketing Mix dan Lingkungan Sosial Terhadap Keputusan Pembelian Online Pakaian Wanita di Kota Padang. EcoGen, 1(4).

Hall, A., Towers, N., \& Shaw, D. R. (2017). Understanding How Millennial Shoppers Decide What to Buy: Digitally Connected Unseen Journeys.International Journal of Retail and Distribution Management, 45(5), 498517. https://doi.org/10.1108/JJRDM-11-2016-0206

Hanaysha, J. R. (2018). An Examination of The Factors Affecting Consumer's Purchase Decision in The Malaysian Retail Market.PSU Research Review, 2(1), 7-23. https://doi.org/10.1108/prr-08-2017-0034

Harris, L. C., \& Goode, M. M. H. (2004).The Four Levels of Loyalty and The Pivotal Role of Trust: A Study of Online Service Dynamics.Journal of Retailing, 80(2), 139-158. https://doi.org/10.1016/j.jretai.2004.04.002 
Hyseni, L., Elliot-Green, A., Lloyd-Williams, F., Kypridemos, O., Flaherty, M., McGill, R., Orton, L., Bromley, H., Cappucio, F. P., \& Capewell, S. (2017). Systematic Review of Dietary Salt Reduction Policies: Evidence For An Effectiveness Hierarchy?. Plos One, https://doi.org/10.1371/journal.pone.0177535.

Hennig-Thurau, T., Gwinner, K. P., Walsh, G., \& Gremler, D. D. (2004). Electronic Word-of-Mouth Via ConsumerOpinion Platforms: What Motivates Consumers to Articulate Themselves On The Internet? Journal of Interactive Marketing, 18(1), 38-52. https://doi.org/10.1002/dir.10073

Istanti, F. (2017). Pengaruh Harga, Kepercayaan, Kemudahan Berbelanja dan E-promosi Terhadap Keputusan Pembelian Belanja Online di Kota Surabaya. Jurnal Bisnis \& Teknologi Politeknik, 4(1), 14-22.

Jacobsen, S. (2018). Why Did I Buy This?:The Effect ofWOM and Online Reviews On Post Purchase Attribution For Product Outcomes. Journal of Research in Interactive Marketing, 12(3), 370-395. https://doi.org/10.1108/JRIM-12-2017-0102

Jeong, H., \& Koo, D. (2015). Combined Effects of Valence and Attributes f E- WOM On Consumer Judgment For Message and Product: The Moderating Effect of Brand Community Type. Internet Research, 25(1), 229.

Kamilullah, J., Kusyanti, A., \& Aryadita, H. (2018). Analisis Pengaruh Kepercayaan, Kepuasan , dan Reputasi Terhadap Loyalitas Konsumen Online Shop dalam Pembelian Produk di Toko XYZ.2(7), 2660-2669.

Kudeshia, C., \& Kumar, A. (2017). Social Ewom: Does it Affect The Brand Attitude and Purchase Intention of Brands? Management Research Review, 40(3), 310-330. https://doi.org/10.1108/MRR-07-2015-0161

Lewis, J. D., \& Weigert, A. (1985). Trust as a Social Reality. Social Forces, 63(4)

Loureiro, S. M. C., Costa, I., \& Panchapakesan, P. (2017). A Passion for Fashion: The Impact of Social Influence, Vanity and Exhibitionism On Consumer Behaviour.International Journal of Retail and Distribution Management, 45(5), 468-484. https://doi.org/10.1108/IRDM-11-2016-0202

Mukayati. (2019). The Influence of Electronic Word of Mouth, Trust and Product Quality on Purchase Decision of Fashion Product Through Online Shop (Case Study : SME 's House of Sabrina in Surabaya). Journal of World Conference. 1, 142-149.

Nurwibowo, R. W., \& Indriani, F. (2017). Analisis Faktor - Faktor yang Mempengaruhi Minat Beli Konsumen Terhadap Produk Fashion Online Melalui Jejaring Sosial Instagram.6, 1-9.

Pan, L., \& Chiou, J. (2011). How Much Can You Trust Online Information? Cues for Perceived Trustworthiness of Consumer-generated Online Information. Journal of Interactive Marketing, 25, 67-74.

Prasad, S., Garg, A., \& Prasad, S. (2018). Purchase Decision of Generation $Y$ in an Online Environment.Marketing Intelligence \& Planning, 37(4), 372-385, https://doi.org/10.1108/MIP-02-20180070.

Punyatoya, P. (2019). Effects of Cognitive and Affective Trust On Online Customer Behavior. Marketing Intelligence and Planning, 37(1), 80-96. https://doi.org/10.1108/MIP-02-2018-0058

Rahman, M. S., Mannan, M. (2018). Consumer Online Purchase Behavior of Local Fashion Clothing Brands: Information Adoption, E-WOM, Online Brand Familiarity and Online Brand Experience. Journal of Fashion Marketing and Management, 22(3), 404-419. https://doi.org/10.1108/JFMM-11-2017-0118

Rehman, F., Yusoff, R., Zabri, S. B. M., Ismail, F. B. (2017). Determinants of Personal Factors in Influencing The Buying Behavior of Consumers in Sales Promotion: A Case of Fashion Industry.

Rooseau, D. M., Burt, R. S., Sitkin, S., \& Camerer, C. F. (1998). Not So Different After All: A Cross-discipline View of Trust. The Academy of Management.

Sekaran, U. (1992). Research Method for Business, A Skill Building Approach. $2^{\text {nd }}$ Edition. New York: John Willey $n$ Sons.

Singh, S., Srivastava, S. (2019). Engaging Consumers in Multichannel Online Retail Environment: A Moderation Study of Platform Type on Interaction of $49 \mathrm{E}$-Commerce and M-Commerce

Susenas. (2018, Juli 23). 9 Kegiatan Masyarakat Indonesia Ketika Mendapat Akses Internet. Retrieved from https://databoks.katadata.co.id/datapublish/2018/07/23/9-kegiatan- masyarakat-indonesia-ketikamendapat-akses-internet

Viswanathan, V., \&Jain, V. (2013). A Dual-System Approach to Understanding "Generation Y" Decision Making. Journal of Consumer Marketing.

Wahyuni, P. R., \& Kurniawan, D. T. (2019). Pengaruh Interaksi Harga dan Desain atau Motif Batik Terhadap Keputusan Pembelian Batik.Cemara, 16(1) 
We Are Social. (2018, Februari 2). Produk Fesyen dan Kecantikan Paling Diminati di Belanja Online. Retrieved from https://databoks.katadata.co.id/datapublish/2018/02/07/produks-fesyen-dan 50 kecantikan-palingdiminati-di-belanja-online

Widyastutir, S., \& Said, M. (2017). Consumer Consideration in Purchase Decision of SPECS Sports Shoes Product Through Brand Image, Product Design and Price Perception. International Journal of Supply Chain Management, 6(4), 199-207.

Wiedmann, K., Hennigs, N., \&Siebels, A. (2009). Value-Based Segmentation of

Zhang, T., Omran, B. A., \& Cobanoglu, C. (2017). Generation Y's Positive and Negative Ewom: Use of Social Media and Mobile Technology. International Journal of Contemporary Hospitality Management, 29(2), 732-761 